\title{
Perspectives on Incentive Spirometry Utility and Patient Protocols
}

\author{
Adam E M Eltorai MSc, Grayson L Baird PhD, Ashley Szabo Eltorai MD, Joshua Pangborn, \\ Valentin Antoci Jr MD PhD, H Allethaire Cullen MSN RN, Katherine Paquette PhD RN, \\ Kevin Connors RRT CPFT, Jacqueline Barbaria RRT, Kimberly J Smeals RRT, \\ Saurabh Agarwal MD, Terrance T Healey MD, Corey E Ventetuolo MD MS, \\ Frank W Sellke MD, and Alan H Daniels MD
}

\begin{abstract}
BACKGROUND: Incentive spirometry (IS) is widely used to prevent postoperative pulmonary complications, despite limited clinical effectiveness data and a lack of standardized use protocols. We sought to evaluate health care professionals' perspectives on IS effectiveness and use procedures. METHODS: An online survey was distributed via social media and newsletters to relevant national nursing and respiratory care societies. Attitudes concerning IS were compared between the American Association for Respiratory Care (AARC) and the nursing societies. RESULTS: A total of 1,681 responses $(83.8 \%$ completion rate) were received. The clear majority of these respondents agreed that IS is essential to patient care $(\mathbf{9 2 . 7 \%})$, improves pulmonary function $(\mathbf{9 2 . 0} \%)$, improves inspiratory capacity $(\mathbf{9 3 . 0} \%)$, helps to prevent $(\mathbf{9 6 . 6 \%})$ and to reverse $(90.0 \%)$ atelectasis, helps to prevent $(\mathbf{9 2 . 5 \%})$ and to reverse $(\mathbf{6 8 . 4 \%})$ pneumonia, and is as effective as early ambulation $(\mathbf{7 4 . 0 \%})$, deep-breathing exercises $(\mathbf{8 8 . 2 \%})$, and directed coughing (79.8\%). Furthermore, most health care professionals believed that IS should be used routinely preoperatively $(78.1 \%)$ and postoperatively (91.1\%), used every hour (59.8\%), used for an average of 9.6 (95\% CI 9.3-9.9) breaths per session, used to achieve breath holds of $7.8(95 \%$ CI 7.4-8.2) $\mathrm{s}$, used to reach an initial target inspiratory volume of $1,288.5(95 \%$ CI $1,253.8-1,323.2) \mathrm{mL}$, and used to achieve a daily inspiratory volume improvement of $525.6(95 \%$ CI $489.8-561.4) \mathrm{mL}$. Of all respondents, $89.6 \%$ believed they received adequate IS education and training. Respondents from the AARC endorsed significantly less agreement relative to the nursing societies on most parameters for IS utility. CONCLUSIONS: There was a major discrepancy between health care professionals' beliefs and the published clinical effectiveness data supporting IS. Despite reported adequate education on IS, variability in what health care professionals believed to be appropriate use underscores the literature's lack of standardization and evidence for specific use procedures. Key words: incentive spirometry; nurse; respiratory therapy; postoperative care; perspectives. [Respir Care 2018;63(5):519-531. (C) 2018 Daedalus Enterprises]
\end{abstract}

\section{Introduction}

In the United States, $95 \%$ of hospitals report prescribing postoperative incentive spirometry (IS). ${ }^{1}$ IS is ordered for

Drs Baird, Antoci, Agarwal, Healey, Ventetuolo, Sellke, and Daniels, as well as Messrs Eltorai and Pangborn, are affiliated with the Warren Alpert Medical School of Brown University, Providence, Rhode Island. Drs Baird and Ventetuolo, as well as Mr Connors, Ms Barbaria, and Ms Smeals, are affiliated with Rhode Island Hospital, Providence, Rhode Island. Dr Eltorai is affiliated with Yale University School of Medicine, New Haven, Connecticut. Ms Cullen is affiliated with the Community College of Rhode Island, Warwick, Rhode Island. Ms Paquette is affiliated with the University of Rhode Island, Kingston, Rhode Island. patients at risk for postoperative pulmonary complications to reduce that risk..$^{2-4}$ According to the American Association for Respiratory Care (AARC), ${ }^{5}$ IS is indicated for

\footnotetext{
Disclosures: Mr Eltorai has disclosed a relationship with Springer and Lippincott Williams \& Wilkins. Dr Daniels has disclosed relationships with DePuy, Globus Medical, Orthofix, Springer, and Stryker.
}

Correspondence: Adam E M Eltorai MSc, Warren Alpert Medical School of Brown University, 100 Butler Drive, Providence, RI 02906. E-mail: adam_eltorai@brown.edu.

DOI: $10.4187 /$ respcare. 05872 
patients with atelectasis and for those with the following risk factors for atelectasis: thoracic or abdominal surgery, ${ }^{2}$ coronary artery bypass graft surgery, ${ }^{67}$ patients wearing binders on the thorax or abdomen, prolonged bed rest, COPD, poor pain control, ${ }^{8}$ neuromuscular lung disease, inspiratory capacity $<2.5 \mathrm{~L},{ }^{9}$ spinal cord injuries, and sickle cell patients with acute chest syndrome. ${ }^{8,10}$ There are no IS guidelines from the American Thoracic Society. The AARC guidelines ${ }^{5}$ describe a procedure of sustaining maximal inhalation for $5 \mathrm{~s}$.

However, numerous studies including controlled trials have demonstrated that IS alone is inadequate in reducing postoperative pulmonary outcomes. ${ }^{6,11-14}$ Early mobilization, deep-breathing exercises, directed cough, and adequate pain management appear to reduce postoperative pulmonary complications ${ }^{15-17}$ with or without IS after cardiothoracic surgery ${ }^{18-24}$ and abdominal surgery. ${ }^{25-31}$ In combined analyses, ${ }^{22,28,32-35}$ IS has repeatedly failed to demonstrate evidence of lung volume improvement or postoperative pulmonary complication reduction. Furthermore, there are few outcome-based data supporting precisely how IS should be used. Previous investigations themselves have used widely variable procedural parameters with respect to the optimal frequency of sessions, $8,11,14,26,36-51$ target inspiratory volume, ${ }^{14,40,43,44}$ whether the target is static or dynamic, ${ }^{11,14,40,42}$ when to start IS postoperatively, ${ }_{11,37,39,40,43,44,47,50}$ the number of breaths per session, $, 8,14,26,36-38,42,43,45,46,49,52,53$ and duration of breath holds. $5,12,14,26,40,42,44,48$

Given their continued widespread usage, the paucity of effectiveness data, and an absence of standardized use protocols, the purpose of this study was to evaluate health care professional perspectives on IS utility and use procedures.

\section{Methods}

A Lifespan Corporation (Providence, Rhode Island) institutional review board-exempt, anonymous, online survey created in REDCap ${ }^{54}$ was distributed from September 2016 to December 2016 via social media and newsletters to the following national nursing and respiratory care societies: Academy of Medical-Surgical Nurses (AMSN), American Association of Critical-Care Nurses (AACN), American Society of Peri-Anesthesia Nurses (ASPAN), and American Association for Respiratory Care (AARC). AMSN is a nursing specialty organization of $>11,500$ medical-surgical nurses. With $>100,000$ members, AACN is a nursing specialty organization of acute and critical care nurses. ASPAN has $>15,000$ members and is a professional organization focused on peri-anesthesia nursing. With $>52,000$ members, AARC is a professional organization for respiratory care. Survey instructions indicated that the goal of the investigation was to understand health care professionals' perspec-

\section{QUICK LOOK}

\section{Current knowledge}

Incentive spirometry (IS) is widely used to prevent postoperative pulmonary complications. There are limited clinical efficacy data and a lack of standardized use protocols.

\section{What this paper contributes to our knowledge}

There was a major discrepancy between providers' beliefs and the published clinical efficacy data supporting IS. Despite reported adequate education on IS, variability in what providers believed to be appropriate use underscores the literature's lack of standardization and evidence for specific use procedures.

tives on the use of IS in their clinical practices and to explore health care professionals' understanding of IS, reflecting actual implementation of IS in patient care.

Analyses were conducted using SAS Software 9.4 (SAS, Cary, North Carolina). Frequencies and percentages were calculated using PROC FREQ, and, for ease of summarization, means and medians were also calculated. Because Likert-scale responses were between 1 and 6, means were calculated using generalized linear modeling, assuming a binomial distribution, thus allowing confidence intervals to be asymmetrical. Mean estimates of count and time were estimated using generalized linear modeling, assuming a negative binomial distribution. All modeling was accomplished using GLIMMIX. Medians were calculated with PROC MEANS. All interval estimates were calculated for 95\% confidence. Finally, post hoc comparisons were made to explore differences between respiratory therapists (AARC) and nurses (ASPAN, AACN, AMSN). Multiple comparisons were made using generalized linear modeling assuming a binomial distribution with Bonferroni corrections. Alpha was set at the 0.05 level for all analyses, and all interval analyses were calculated for $95 \%$ confidence.

\section{Results}

There were 1,681 unique respondents from the 4 national organizations. The respondents included respiratory therapists and nurses with various educational backgrounds, years of experience, and primary practice locations (Table 1). Survey completion rates were $80.3 \%$ for AARC, $84.3 \%$ for ASPAN, $84.8 \%$ for AMSN, and $90.1 \%$ for AACN. Given the distribution methodology, the exact response rates cannot be determined due to the inability to identify the total number of individuals the survey may have reached. 


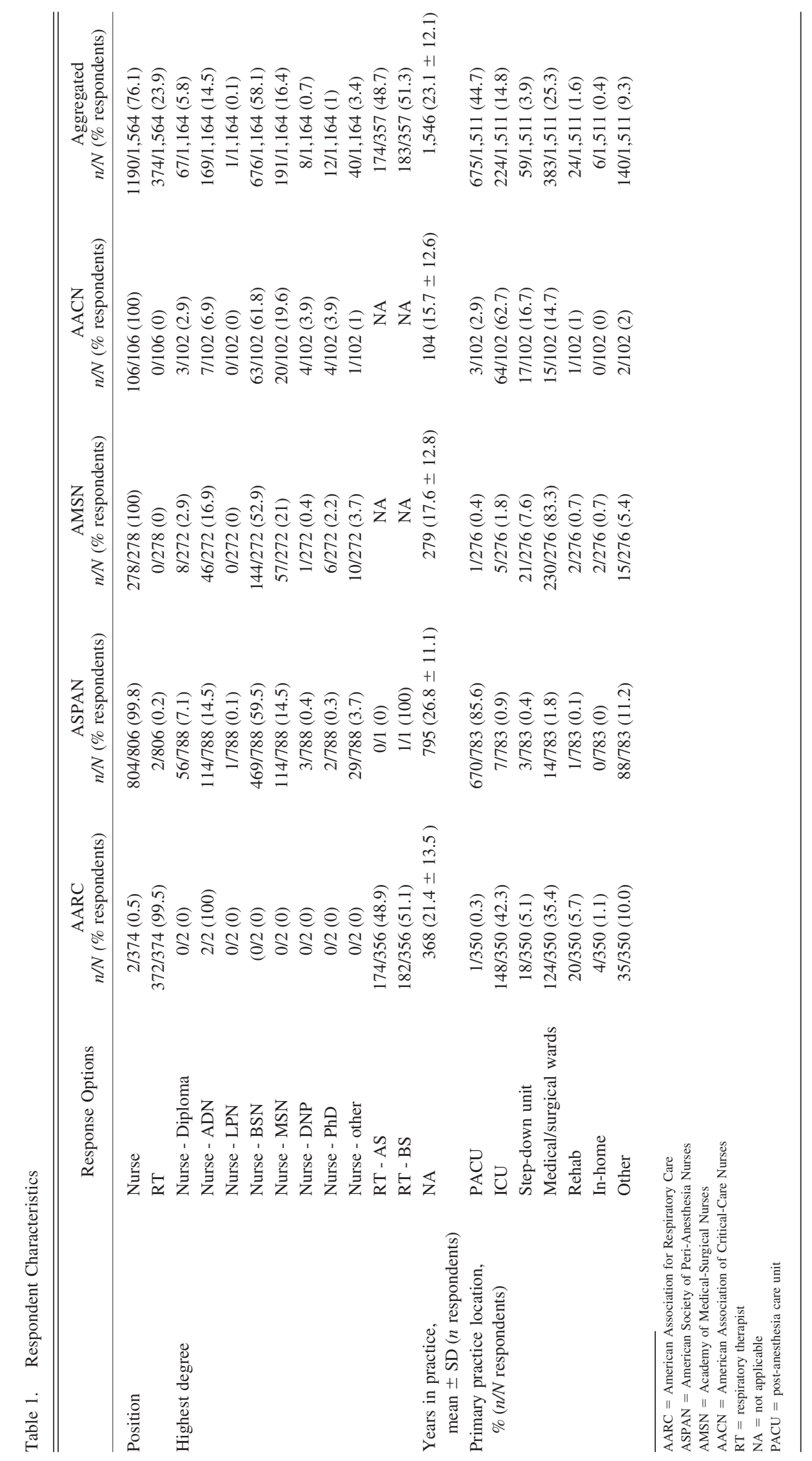


However, based on organization-reported memberships, estimated response rates were $5.4 \%$ for ASPAN, $2.4 \%$ for AMSN, $0.7 \%$ for AARC, and $0.1 \%$ for AACN.

From the survey responses, the clear majority of health care professionals agreed that IS is essential to patient care (92.7\%; 1,531 of 1,651 respondents) (Table 2). Most health care professionals agreed that IS improves pulmonary function $(92.0 \%$; 1,511 of 1,643 respondents) and improves inspiratory capacity (93.0\%; 1,525 of 1,639 respondents) (Table 3). Most health care professionals agreed that IS helps to prevent $(96.6 \%$; 1,593 of 1,650 respondents) and to reverse $(90.0 \% ; 1,477$ of 1,641 respondents) atelectasis, and IS helps to prevent $(92.5 \%$; 1,522 of 1,646 respondents) and to reverse (68.4\%; 1,117 of 1,632 respondents) pneumonia (Table 4). Most health care professionals agreed that IS is as effective as early ambulation $(74.0 \% ; 1,214$ of 1,641 respondents), deep-breathing exercises $(88.2 \% ; 1,456$ of 1,650 respondents), and directed coughing (79.8\%; 1,308 of 1,640 respondents) (Table 5). Most health care professionals agreed that IS should be used routinely preoperatively $(78.1 \% ; 1,281$ of 1,640 respondents) and postoperatively $(91.1 \% ; 1,504$ of 1,651 respondents) (Table 6).

Most health care professionals agreed that IS should be used every hour $(59.8 \% ; 961$ of 1,606 respondents). Health care professionals believed an average of $9.6(95 \% \mathrm{CI}$ 9.3-9.9) breaths should be taken per session, with breath holds of 7.8 (95\% CI 7.4-8.2) s, initial target inspiratory volume of $1,288.5$ (95\% CI $1,253.8-1,323.2) \mathrm{mL}$, and daily inspiratory volume improvement of 525.6 (95\% CI 489.8-561.4) mL. In terms of appropriate use, $51.1 \%$ (829 of 1,621) of respondents believed that achieving target inspiratory volume is the most important factor, with piston hovering in the "smiley-face" zone to be the target inspiratory flow (72.5\%; 1,176 of 1,623 respondents) (Table 7). Most respondents believed they received adequate IS education and training (89.6\%; 1,474 of 1,645 respondents) (Table 8).

Finally, attitudes concerning IS were compared between AARC and the nursing societies. As seen in the estimates in Tables 2-6 and 8, AARC members endorsed significantly less agreement relative to the nursing societies concerning the following statements:

- IS is essential for patient care $(P<.001)$.

- IS improves pulmonary function $(P<.001)$.

- IS improves inspiratory capacity $(P<.001)$.

- IS helps to prevent atelectasis $(P<.001)$.

- IS helps to reverse atelectasis $(P<.001)$.

- IS helps to prevent pneumonia $(P<.0001)$.

- IS helps to reverse pneumonia $(P<.001)$.

- IS should be used routinely preoperatively $(P<.001)$.

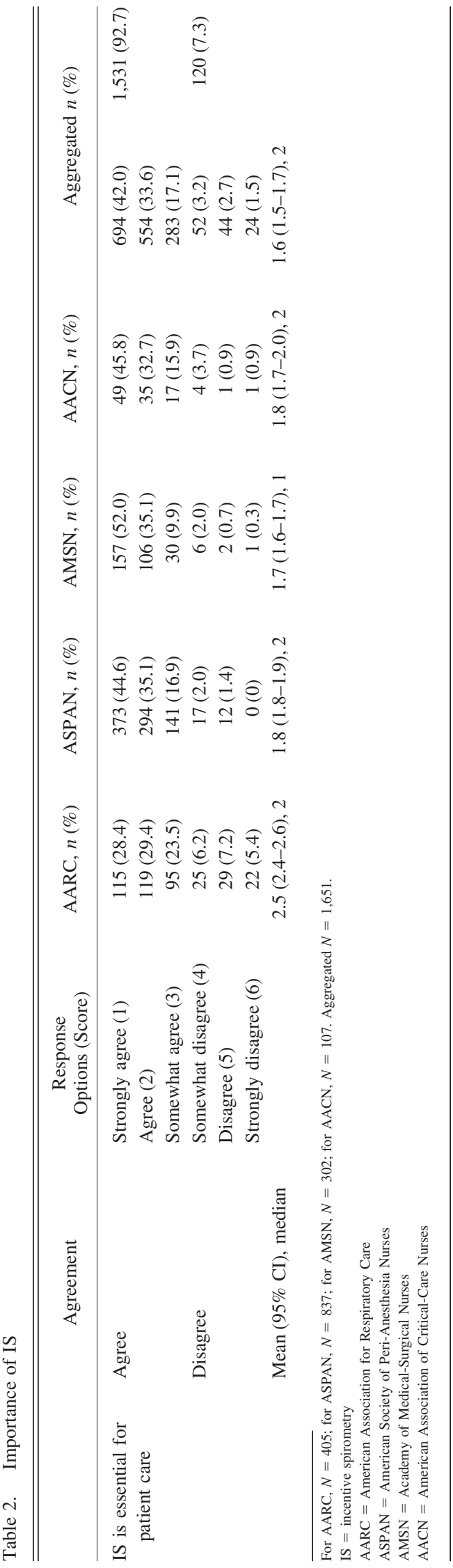




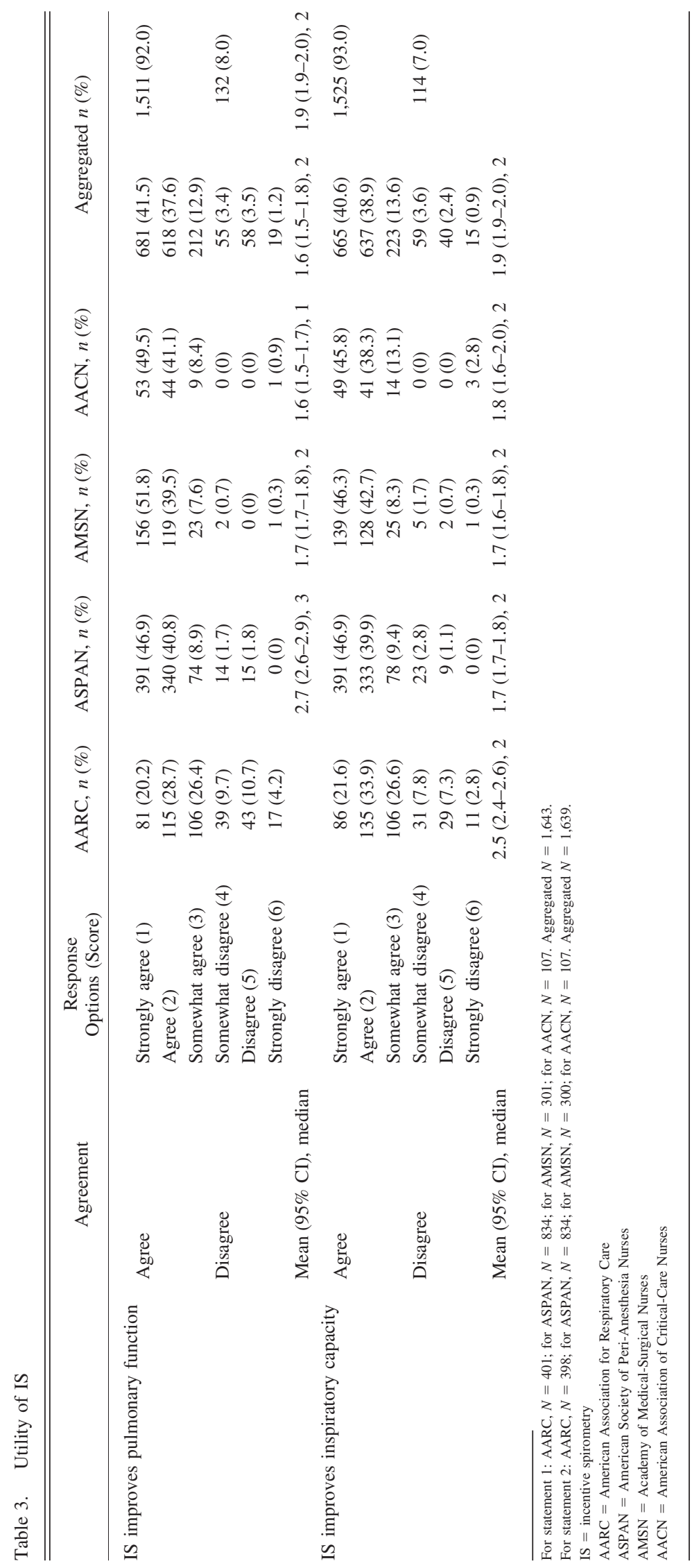




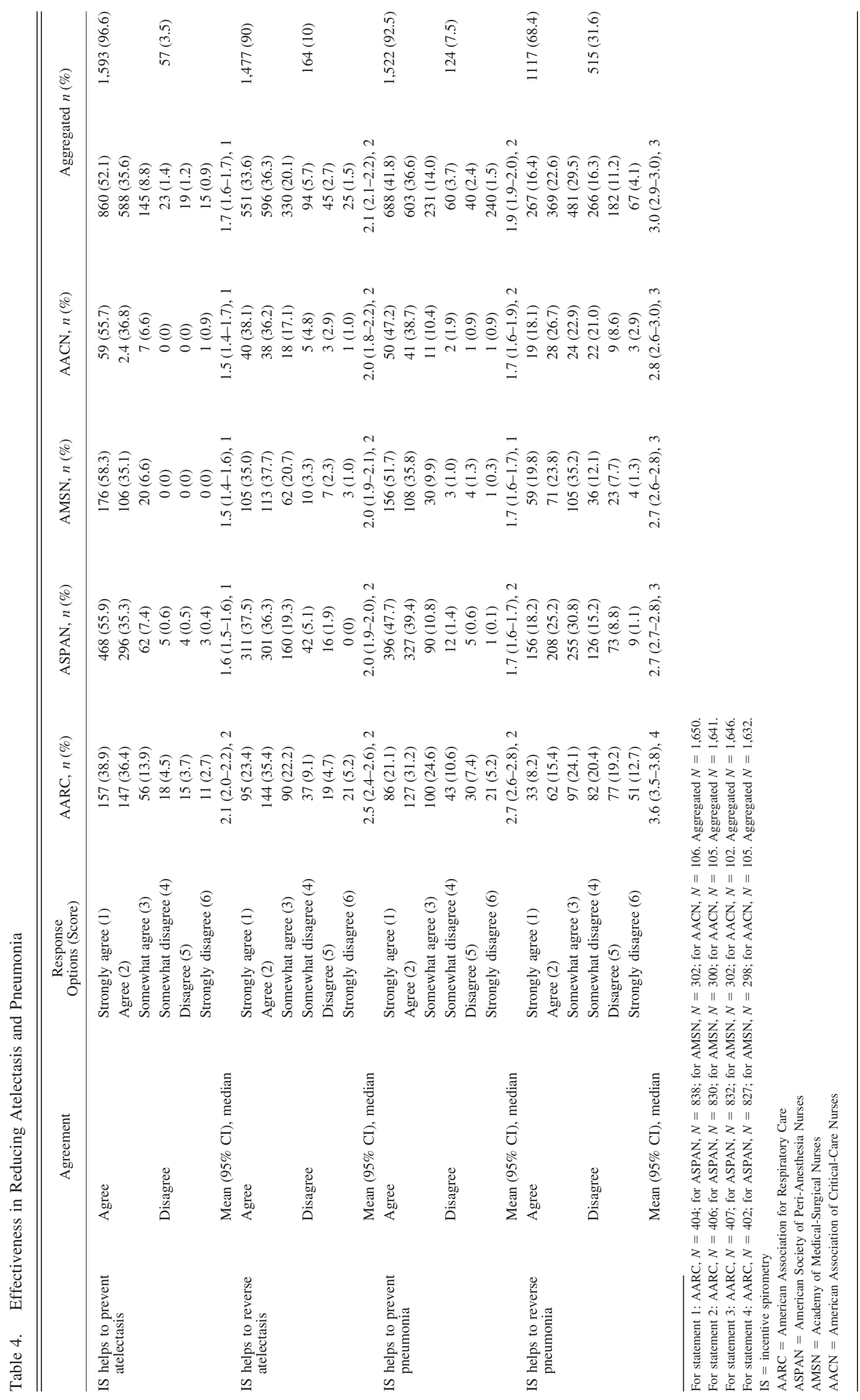




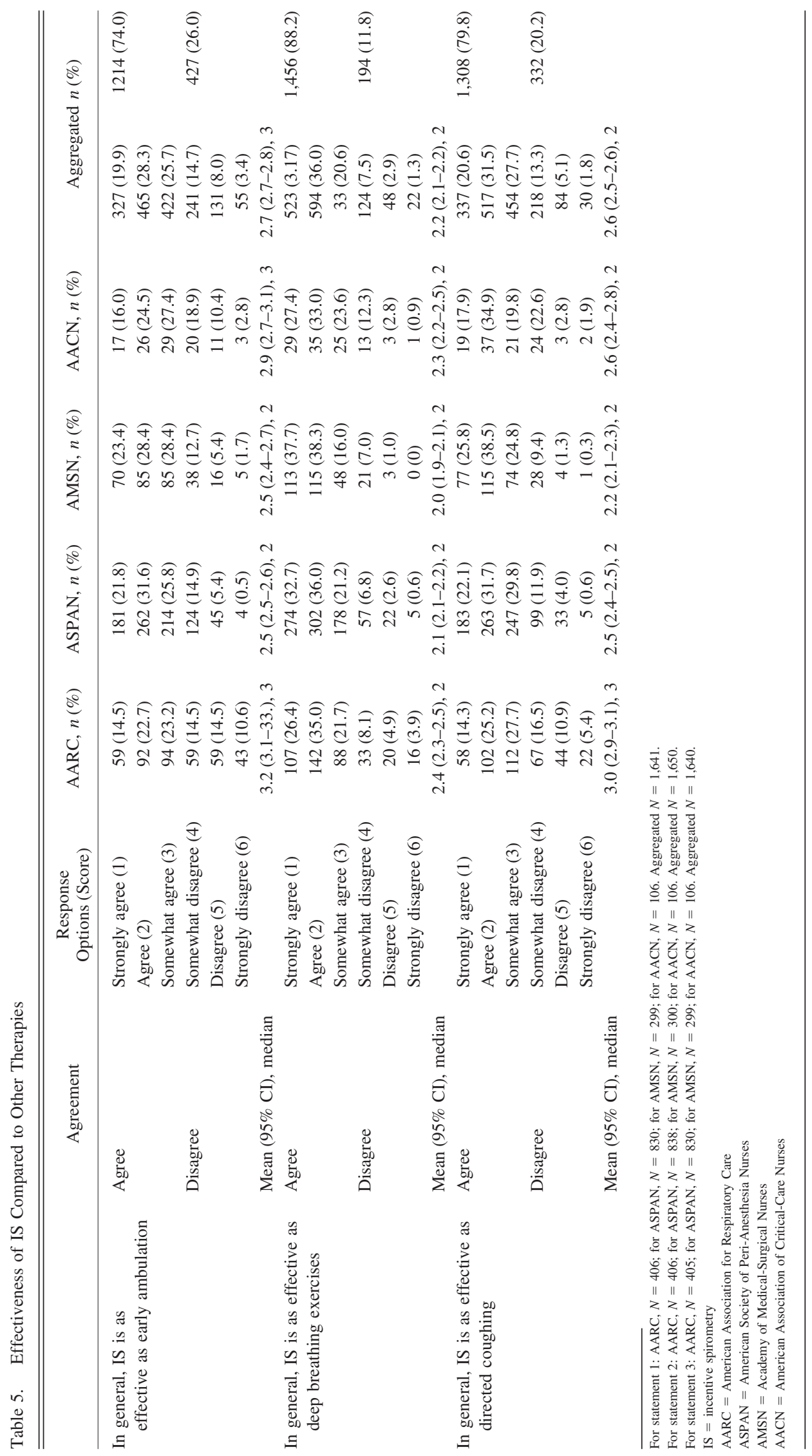




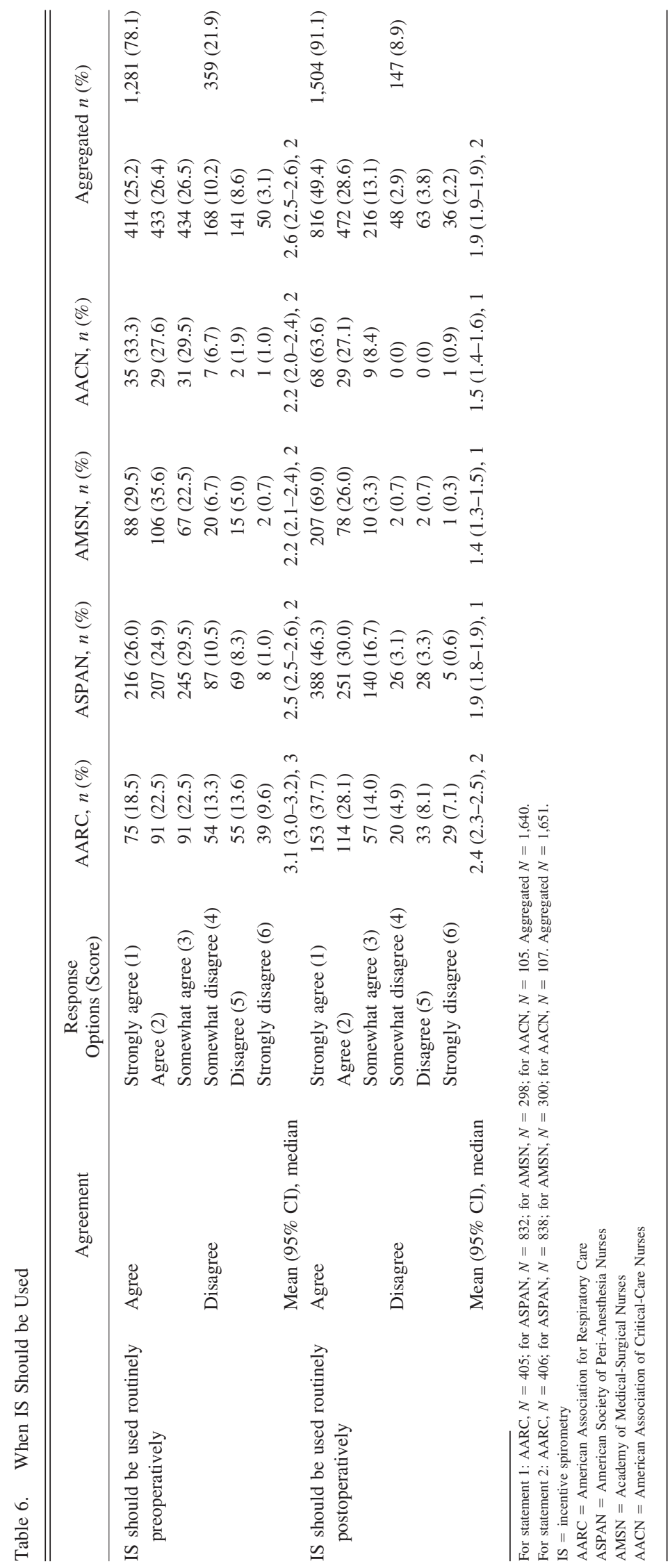




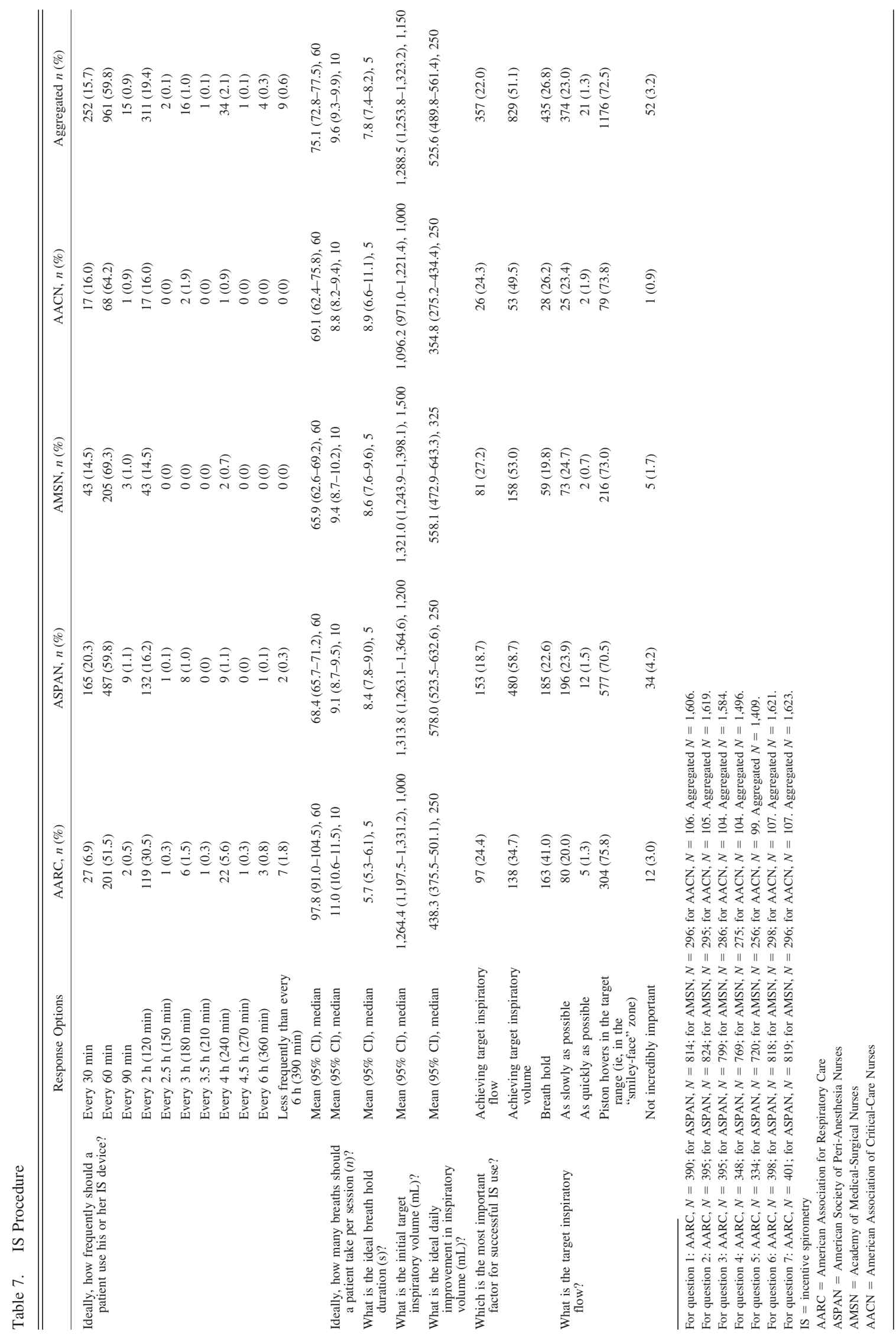




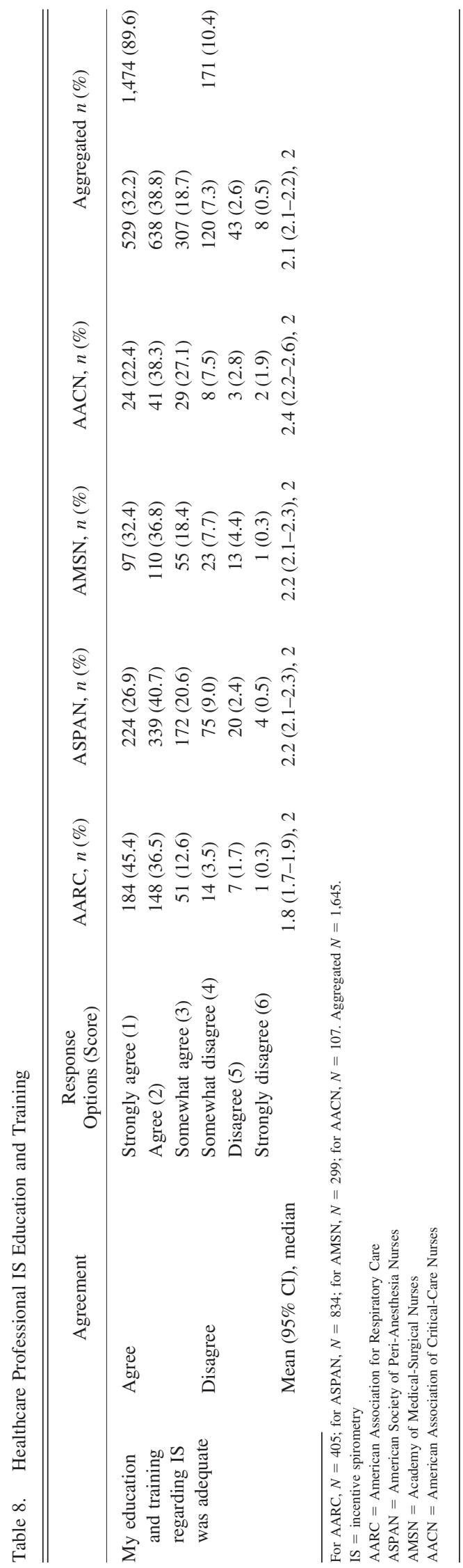

- IS should be used routinely postoperatively $(P<.001)$.

- In general, IS is as effective as early ambulation $(P<.05)$.

- In general, IS is as effective as deep-breathing exercises $(P<.001)$, except AACN versus AARC were not different, $P>.99$.

- In general, IS is as effective as directed coughing $(P<.001)$.

- My education and training regarding IS was adequate $(P<.001)$.

\section{Discussion}

This investigation represents a large national survey of health care professionals' perspectives on IS effectiveness and use. Despite a dearth of supportive clinical evidence, ${ }^{22,28,32-35}$ most health care professionals believed that IS is essential to patient care, improves clinical outcomes, and is as effective as other postoperative respiratory therapies. Furthermore, despite the paucity of substantiating evidence, health care professionals collectively had strong opinions regarding use procedures with respect to frequency of use, number of breaths per session, breath-hold duration, and initial target inspiratory volumes and flow. Nevertheless, nearly all respondents believed they received adequate IS education and training.

IS has been clinically compared to other postoperative respiratory therapies. Although 2 studies found beneficial effects of IS on postoperative pulmonary complications compared to intermittent positive-pressure breathing ${ }^{39}$ which has been proven ineffective ${ }^{55}$ - and physiotherapy ${ }^{37}$ for upper abdominal surgery patients, most show no differences ${ }^{11,12,26,44,47,48,56}$ or inferior effects (vs intermittent positive-pressure breathing ${ }^{14}$ and $\mathrm{CPAP}^{50}$ ). In 1 investigation, IS appeared to facilitate faster tidal volume recovery to preoperative baseline versus conventional physical therapy, ${ }^{57}$ whereas most other studies have demonstrated no advantages ${ }^{11,12,26,46,47,56}$ or inferior ${ }^{40}$ pulmonary function improvement compared to other respiratory therapies. Past investigations have also reported no difference between IS and other respiratory techniques in reducing postoperative pulmonary complications $\mathbf{s}^{6,24,40,43,52,53,58-60}$ or improving pulmonary function in cardiothoracic surgical patients. ${ }^{24,45,52,53,60}$

Further clinical research is required to determine optimal IS protocols. Previous investigators have recommended that IS usage occur hourly, ${ }^{26,36,37}$ every $2 \mathrm{~h}, 8,38-402$ times per day, ${ }^{41,42} 4$ times per day, ${ }^{14,43,44} 5$ times per day, ${ }^{45}$ 12 times per day, ${ }^{11}$ every $4 \mathrm{~h},{ }^{46} 4$ times per hour, ${ }^{47} 3$ times per hour, ${ }^{48} 10$ times per hour, ${ }^{49} 30$ times per hour, ${ }^{50}$ or every $10 \mathrm{~min} .{ }^{51}$ Past studies set subjects' target inspiratory volume at $50-70 \%$ of preoperative vital capacity, ${ }^{14} 1,400-$ 
$1,770 \mathrm{~mL},{ }^{44}$ at $200-2,000 \mathrm{~mL},{ }^{40}$ or at maximal inspiration above residual volume. ${ }^{43}$ Subjects have been instructed to complete 3 breaths per session, ${ }^{42} 3-5$ breaths per session, ${ }^{49,52} 5$ breaths per session, ${ }^{53} 10$ breaths per session, $, 8,14,26,36,37,43,4515$ breaths per session, ${ }^{46}$ and 20 breaths per session. ${ }^{38}$

Outside AARC guidelines ${ }^{5}$ of 5 -s breath holds, previous studies have used $3 \mathrm{~s}^{14,40,42,44,48}$ or have suggested holding the breath for as long as possible. ${ }^{12,26}$ Previous methodologies have called for IS usage at various times after surgery, including during the first $3 \mathrm{~d}$ after surgery, ${ }^{11}$ starting $4-72 \mathrm{~h}$ after surgery, ${ }^{40}$ both preoperatively and during the first $5 \mathrm{~d}$ after surgery, ${ }^{37}$ for $5 \mathrm{~d}$ after surgery, ${ }^{39}$ through postoperative day $3,{ }^{44}$ for postoperative days $1-4,{ }^{47}$ starting $1 \mathrm{~h}$ after surgery for $3 \mathrm{~d}, 50$ and starting $4 \mathrm{~h}$ after extubation. ${ }^{43}$ Certain studies report changing their use procedure during the hospital course, including increasing inspiratory target volume, ${ }^{14,40}$ increasing both volume and breath-hold duration, ${ }^{11}$ and decreasing frequency. ${ }^{42}$

Data from this investigation were consistent with the disparate IS protocols reported in the literature. Most health care professionals did report that they received adequate IS training and education, so the discrepancy likely reflects the lack of evidence-based standard protocols and presents an opportunity for further research. Guidelines may be developed for individual practice settings and patient subgroups as well. Furthermore, results from this investigation suggest that a majority of health care professionals agreed with many of the statements; however, for a low-risk intervention, the variability in the level of agreement may indicate that health care professionals recognize the dearth of evidence. High levels of agreement may indicate clinical observations that precede substantiation by clinical studies or widely disseminated myths-both explanations serve as a call for well-designed studies. With respondents indicating that they received adequate education on IS, the question of non-evidence-based material being taught is raised. If health care professionals' practice is consistent with what they learned in training, then school or clinical training offers an opportunity to introduce and integrate evidence-based care into future practice.

Comparing the results from this study to health care professionals' perspectives on other low-risk interventions may offer insight into the extent to which health care professionals are aware of the paucity of evidence and highlight the need for further investigation. Further investigation into differences among health care professional groups (eg, professional organization, position, degree, years of experience, practice location, types of patients) may provide additional important insight into the development of health care professionals' perspectives. Comparing the different types of available IS devices could be another interesting avenue of investigation.
The health care professionals' strong opinions about the effectiveness of IS despite the lack of supporting data also serves as an interesting case study in translating evidence into practice. Despite the absence of such granular data, why certain responses on the utility of IS (eg, helps to prevent atelectasis) had greater agreement than other utility statements may shed light on differences in health care professionals' practices and protocols. Practice should not be driven by opinion, but by evidence. Therefore, further investigation is needed to assess where such beliefs originate-education, training, or experience.

This investigation has several potential limitations. Health care professionals from only 4 respiratory therapy and nursing societies were sampled. We do not know the exact response rate from those who were sampled, although our survey completion rate was very high (83.8\%). This may create a sampling bias where being a member of a given society predisposes respondents to certain perspectives on IS. Ideally, survey responses would be collected from all nurses and respiratory therapists across the country. The data suggest respondents believe in the use of IS in their clinical contexts. This could be due to a survey bias, a lack of understanding of the evidence, or respondents' own clinical experience.

Additional well-designed randomized clinical trials are needed to evaluate IS methods for improvement. Only then can a real determination of whether IS use improves clinical outcomes occur. Further study is needed to determine which specific patient groups may benefit from IS, the costs of implementing IS, and optimal IS use protocols.

\section{ACKNOWLEDGMENTS}

The authors are appreciative of the national societies for assisting with survey distribution and thank the following individuals for their collaboration: Kristen Francoeur MSN RN for critical review of the manuscript for important intellectual content; Susan Russell RN JD for critical review of the manuscript for important intellectual content; Barbara Riley DNP RN NEA-BC for critical review of the manuscript for important intellectual content and for substantial contributions to conception; Paula Gellner MSN for critical review of the manuscript for important intellectual content and for substantial contributions to conception; and $\mathrm{M}$ Kelly Murphy, Samantha Norris, Renee David, Tina Calise, Katelyn DeCarlo, and Jack A Elias for substantial contributions to conception.

\section{REFERENCES}

1. O'Donohue WJ. National survey of the usage of lung expansion modalities for the prevention and treatment of postoperative atelectasis following abdominal and thoracic surgery. Chest 1985;87(1): 76-80.

2. Westwood K, Griffin M, Roberts K, Williams M, Yoong K, Digger $\mathrm{T}$. Incentive spirometry decreases respiratory complications following major abdominal surgery. Surgeon 2007;5(6):339-342.

3. Kips J. Preoperative pulmonary evaluation. Acta Clin Belg 1997; 52(5):301-305. 


\section{NuRSE AND RT PERSPECTIVES ON IS}

4. Larson CM, Ratzer ER, Davis-Merritt D, Clark JR. The effect of abdominal binders on postoperative pulmonary function. Am Surg 2009;75(2):169-171.

5. Restrepo RD, Wettstein R, Wittnebel L, Tracy M. Incentive spirometry: 2011. Respir Care 2011;56(10):1600-1604.

6. Yanez-Brage I, Pita-Fernandez S, Juffe-Stein A, Martinez-Gonzalez U, Pertega-Diaz S, Mauleon-Garcia A. Respiratory physiotherapy and incidence of pulmonary complications in off-pump coronary artery bypass graft surgery: an observational follow-up study. BMC Pulm Med 2009;9:36.

7. Pappachen S, Smith PR, Shah S, Brito V, Bader F, Khoury B. Postoperative pulmonary complications after gynecologic surgery. Int $\mathrm{J}$ Gynaecol Obstet 2006;93(1):74-76.

8. Bellet PS, Kalinyak KA, Shukla R, Gelfand MJ, Rucknagel DL. Incentive spirometry to prevent acute pulmonary complications in sickle cell diseases. N Engl J Med 1995;333(11):699-703.

9. Weindler J, Kiefer RT. The efficacy of postoperative incentive spirometry is influenced by the device-specific imposed work of breathing. Chest 2001;119(6):1858-1864.

10. Hsu LL, Batts BK, Rau JL. Positive expiratory pressure device acceptance by hospitalized children with sickle cell disease is comparable to incentive spirometry. Respir Care 2005;50(5):624-627.

11. Schwieger I, Gamulin Z, Forster A, Meyer P, Gemperle M, Suter PM. Absence of benefit of incentive spirometry in low-risk patients undergoing elective cholecystectomy. Chest 1986;89(5):652-656.

12. Hall JC, Tarala R, Harris J, Tapper J, Christiansen K. Incentive spirometry versus routine chest physiotherapy for prevention of pulmonary complications after abdominal surgery. Lancet 1991; 337(8747):953-956.

13. Melendez JA, Alagesan R, Reinsel R, Weissman C, Burt M. Postthoracotomy respiratory muscle mechanics during incentive spirometry using respiratory inductance plethysmography. Chest 1992; 101(2):432-436.

14. Celli BR, Rodriguez KS, Snider GL. A controlled trial of intermittent positive pressure breathing, incentive spirometry, and deep breathing exercises in preventing pulmonary complications after abdominal surgery. Am Rev Respir Dis 1984;130(1):12-15.

15. Ballantyne JC, Carr DB, deFerranti S, Suarez T, Lau J, Chalmers $\mathrm{TC}$, et al. The comparative effects of postoperative analgesic therapies on pulmonary outcome: cumulative meta-analyses of randomized, controlled trials. Anesth Analg 1998;86(3):598-612.

16. Desai PM. Pain management and pulmonary dysfunction. Crit Care Clin 1999;15(1):151-166

17. Winters BA. Older adults with traumatic rib fractures: an evidencebased approach to their care. J Trauma Nurs 2009;16(2):93-97.

18. Weiner P, Man A, Weiner M, Rabner M, Waizman J, Magadle R, et al. The effect of incentive spirometry and inspiratory muscle training on pulmonary function after lung resection. J Thorac Cardiovasc Surg 1997;113(3):552-557.

19. Agostini P, Singh S. Incentive spirometry following thoracic surgery: what should we be doing? Physiotherapy 2009;95(2):76-82.

20. Gosselink R, Schrever K, Cops P, Witvrouwen H, De Leyn P, Troosters $\mathrm{T}$, et al. Incentive spirometry does not enhance recovery after thoracic surgery. Crit Care Med 2000;28(3):679-683.

21. Varela G, Ballesteros E, Jimenez MF, Novoa N, Aranda JL. Costeffectiveness analysis of prophylactic respiratory physiotherapy in pulmonary lobectomy. Eur J Cardiothorac Surg 2006;29(2):216-220.

22. Pasquina P, Tramer MR, Walder B. Prophylactic respiratory physiotherapy after cardiac surgery: systematic review. BMJ 2003; 327(7428): 1379.

23. Dias CM, Vieira Rde O, Oliveira JF, Lopes AJ, Menezes SL, Guimaraes FS. Three physiotherapy protocols: effects on pulmonary volumes after cardiac surgery. J Bras Pneumol 2011;37(1):54-60.
24. Crowe JM, Bradley CA. The effectiveness of incentive spirometry with physical therapy for high-risk patients after coronary artery bypass surgery. Phys Ther 1997;77(3):260-268.

25. Mang H, Kacmarek RM. Prevention of pulmonary complications after abdominal surgery. Lancet 1991;338(8762):312-313.

26. Hall JC, Tarala RA, Tapper J, Hall JL. Prevention of respiratory complications after abdominal surgery: a randomised clinical trial. BMJ 1996;312(7024):148-152.

27. Thomas JA, McIntosh JM. Are incentive spirometry, intermittent positive pressure breathing, and deep breathing exercises effective in the prevention of postoperative pulmonary complications after upper abdominal surgery? A systematic overview and meta-analysis. Phys Ther 1994;74(1):3-10.

28. Pasquina P, Tramer MR, Granier JM, Walder B. Respiratory physiotherapy to prevent pulmonary complications after abdominal surgery: a systematic review. Chest 2006;130(6):1887-1899.

29. Guimaraes MM, El Dib R, Smith AF, Matos D. Incentive spirometry for prevention of postoperative pulmonary complications in upper abdominal surgery. Cochrane Database Syst Rev 2009; (3):CD006058.

30. Bapoje SR, Whitaker JF, Schulz T, Chu ES, Albert RK. Preoperative evaluation of the patient with pulmonary disease. Chest 2007;132(5): 1637-1645.

31. Vats N. Effect of deep breathing exercises and incentive spirometry in the prevention of postoperative pulmonary complications in the patients of cancer esophagus undergoing esophagectomy. Ind J Physiother Occup Ther 2009;3(3):321-325.

32. Overend TJ AC, Lucy SD, Bhatia C, Jonsson BI, Timmermans C. The effect of incentive spirometry on postoperative pulmonary complications. Chest 2001;120(3):971-978.

33. Carvalho CR, Paisani DM, Lunardi AC. Incentive spirometry in major surgeries: a systematic review. Rev Bras Fisioter 2011;15(5): 343-350.

34. Freitas ER, Soares BG, Cardoso JR, Atallah AN. Incentive spirometry for preventing pulmonary complications after coronary artery bypass graft. Cochrane Database Syst Rev 2012;(9):CD004466.

35. do Nascimento Junior P, Modolo NS, Andrade S, Guimaraes MM, Braz LG, El Dib R. Incentive spirometry for prevention of postoperative pulmonary complications in upper abdominal surgery. Cochrane Database Syst Rev 2014;(2):CD006058.

36. Rafea A WK, Amin H, El-Sabagh R, Yousef S. Flow-oriented incentive spirometer versus volume-oriented spirometer training on pulmonary ventilation after upper abdominal surgery. Egypt J Brochoscopy 2009;3(2).

37. Craven JL, Evans GA, Davenport PJ, Williams RHP. The evaluation of the incentive spirometer in the management of postoperative pulmonary complications. Br J Surg 1974;61(10):793-797.

38. Matte P, Jacquet L, Van Dyck M, Goenen M. Effects of conventional physiotherapy, continuous positive airway pressure and non-invasive ventilatory support with bilevel positive airway pressure after coronary artery bypass grafting. Acta Anaesthesiol Scand 2000;44(1):7581.

39. Dohi S, Gold MI. Comparison of two methods of postoperative respiratory care. Chest 1978;73(5):592-595.

40. Stock MC, Downs JB, Gauer PK, Alster JM, Imrey PB. Prevention of postoperative pulmonary complications with CPAP, incentive spirometry, and conservative therapy. Chest 1985;87(2):151-157.

41. Kulkarni SR, Fletcher E, McConnell AK, Poskitt KR, Whyman MR. Pre-operative inspiratory muscle training preserves postoperative inspiratory muscle strength following major abdominal surgery: a randomised pilot study. Ann R Coll Surg Engl 2010;92(8):700-707.

42. Savci S Sakinç S ID, Arikan H, Zehr C, Buran Y, Kuralay E. Active cycle of breathing techniques and incentive spirometer in coronary artery bypass graft surgery. Fizyoterapi Rehabilitasyon 2006;17(2): 61-69. 


\section{NuRse AND RT PERSPeCTIVES ON IS}

43. Dull JL, Dull WL. Are maximal inspiratory breathing exercises or incentive spirometry better than early mobilization after cardiopulmonary bypass? Phys Ther 1983;63(5):655-659.

44. Jung R, Wight J, Nusser R, Rosoff L. Comparison of three methods of respiratory care following upper abdominal surgery. Chest 1980; 78(1):31-35.

45. Renault JA, Costa-Val R, Rosseti MB, Houri Neto M. Comparison between deep breathing exercises and incentive spirometry after CABG surgery. Rev Bras Cir Cardiovasc 2009;24(2):165-172.

46. Kundra P, Vitheeswaran M, Nagappa M, Sistla S. Effect of preoperative and postoperative incentive spirometry on lung functions after laparoscopic cholecystectomy. Surg Laparosc Endosc Percutan Tech 2010;20(3):170-172.

47. Lyager S, Wernberg M, Rajani N, Boggild-Madsen B, Neilsen L, Neilsen HC, et al. Can postoperative pulmonary conditions be improved by treatment with the Bartlett-Edwards incentive spirometer after upper abdominal surgery? Acta Anaesthesiol Scand 1979;23(4): 312-319.

48. O'Connor M, Tattersall MP, Carter JA. An evaluation of the incentive spirometer to improve lung function after cholecystectomy. Anaesthesia 1988;43(9):785-787.

49. Cassidy MR, Rosenkranz P, McCabe K, Rosen JE, McAneny D. I COUGH: reducing postoperative pulmonary complications with a multidisciplinary patient care program. JAMA Surg 2013;148(8): 740-745.

50. Ricksten SE, Bengtsson A, Soderberg C, Thorden M, Kvist H. Effects of periodic positive airway pressure by mask on postoperative pulmonary function. Chest 1986;89(6):774-781.

51. Romanini W, Muller AP, Carvalho KA, Olandoski M, Faria-Neto JR, Mendes FL, et al. The effects of intermittent positive pressure and incentive spirometry in the postoperative of myocardial revascularization. Arq Bras Cardiol 2007;89(2):94-99, 105-110.

52. Jenkins SC, Soutar SA, Loukota JM, Johnson LC, Moxham J. Physiotherapy after coronary artery surgery: are breathing exercises necessary? Thorax 1989;44(8):634-639.

53. Oikkonen M, Karjalainen K, Kahara V, Kuosa R, Schavikin L. Comparison of incentive spirometry and intermittent positive pressure breathing after coronary artery bypass graft. Chest 1991;99(1):60-65.

54. Harris PA, Taylor R, Thielke R, Payne J, Gonzalez N, Conde JG. Research electronic data capture (REDCap)-a metadata-driven methodology and workflow process for providing translational research informatics support. J Biomed Inform 2009;42(2):377-381.

55. Handelsman H. Intermittent positive-pressure breathing (IPPB) therapy. Health Technol Assess Rep 1991;(1):1-9.

56. Cattano D, Altamirano A, Vannucci A, Melnikov V, Cone C, Hagberg CA. Preoperative use of incentive spirometry does not affect postoperative lung function in bariatric surgery. Transl Res 2010; 156(5):265-272.

57. Minschaert M, Vincent JL, Ros AM, Kahn RJ. Influence of incentive spirometry on pulmonary volumes after laparotomy. Acta Anaesthesiol Belg 1982;33(3):203-209.

58. Iverson LI, Ecker RR, Fox HE, May IA. A comparative study of IPPB, the incentive spirometer, and blow bottles: the prevention of atelectasis following cardiac surgery. Ann Thorac Surg 1978;25(3): 197-200.

59. Gale GD, Sanders DE. Incentive spirometry: its value after cardiac surgery. Can Anaesth Soc J 1980;27(5):475-480.

60. Agostini P, Naidu B, Cieslik H, Steyn R, Rajesh PB, Bishay E, et al. Effectiveness of incentive spirometry in patients following thoracotomy and lung resection including those at high risk for developing pulmonary complications. Thorax 2013;68(6):580-585.

This article is approved for Continuing Respiratory Care Education credit. For information and to obtain your CRCE

(free to AARC members) visit www.rcjournal.com

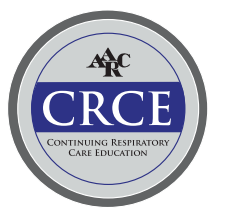

